\title{
EDITORIAL
}

\section{Understanding and Improving Life}

Syed Muhammad Imran Majeed

Creation of knowledge through understanding is a perpetual process for humanity. Our understanding grows through application of logic and scientific methodology which form the basis of research. The endowment of intellectual ability has empowered humans to adopt this course to keep on generating better and deeper understanding of our existential situation. Advancements in technology keep on providing better and better means to facilitate our understanding even more.

Given the accelerating pace of human understanding, the body of our knowledge and the means to improve our living conditions, are growing exponentially. The genome sequencing of the 2019 Corona Virus was accomplished well within a fortnight of the first reported patient. ${ }^{1}$ The development of a prototype vaccine against it, was announced within another two months. ${ }^{2}$ About a couple of decades ago, such processes took over ten times longer when SARS virus outbreak occurred. ${ }^{3,4}$

As we continue to uncover the previous unknowns, we become more and more aware of additional unknowns. Hence, as our knowledge grows, so does the realization of our ignorance. No knowledge is enough knowledge, and no effort at discovery is effort enough. For all to help in this human collective is the spirit to go by.

The launching of Life and Science journal is such a contribution towards 'Understanding and Improving Life' and its conditions, on earth and beyond. This being the motto of the National University of Medical Sciences, Pakistan, from whose platform, the journal is being launched. It is meant to be an international, peer reviewed, open source journal. It intends to address all the dimensions of the eco-bio-psycho-social spectrum of life, as well as the axiology of its existence, the ethics and the aesthetics. The journal welcomes contributions by all, for the benefit of all.

\section{Editor-in-Chief}

doi: https://doi.org/10.37185/LnS.1.1.100

\section{REFERENCES}

1. Lu R, Zhao X, Li J, Niu P, Yang B, Wu H, et al. Genomic characterisation and epidemiology of 2019 novel coronavirus: implications for virus origins and receptor binding. The Lancet. 2020; 395: 391-3.

2. Inovio Collaborating with Beijing Advaccine to Advance INO-4800 Vaccine against New Coronavirus in China. January $30,2020$. http://ir.inovio.com/news-and-media/news/press-release-details/2020/Inovio-Collaborating-With-Beijing-Advaccine-ToAdvance-INO-4800-Vaccine-Against-New-Coronavirus-In China/default.aspx.

3. Cherry JD, Krogstad P. SARS: The First Pandemic of the 21st Century. Pediatric research. 2004; 56: 1-5.

4. Bi S, Xu Z, Li W, Wang J, Hu Y, Liu Y, et al. Complete genome sequences of the SARS-CoV: the BJ Group (Isolates BJ01-BJ04). Genomics, proteomics \& bioinformatics. $2003 ; 1: 180-92$. 